\title{
A Review of Pellet Production from Biomass Residues as Domestic Fuel
}

\author{
Japhet, J. A. ${ }^{1}$, Tokan, A. ${ }^{2}$ and Kyauta, E. E. ${ }^{3}$ \\ ${ }^{1}$ Department of Mechanical Engineering, University of Jos, Nigeria. \\ ${ }^{2,3}$ Department of Mechanical Engineering, Abubakar Tafawa Balewa University, Bauchi, Nigeria.
}

\begin{abstract}
Burning fossil fuels and deforestation are the major contributors to anthropogenic climate change. As a result of climate change threat, the use of biomass and biomass residues have become extremely important to created a new industry focused on the production of clean energy through the use of renewable sources. However, factors such as low density, high moisture content, ease of handling, storage and transport are some disadvantage from the use of biomass. Pelletizing is a promising technology which converts it into a more useful form through densification in order to minimize these disadvantages. Between 2006 and 2012, pellet production worldwide grew from 7 to 19 million tons. However, the use of pellets is insignificant in developing countries. Many of the developing countries produce huge quantities of wood and agro residues with an interesting potential for biomass energy production, but they are used inefficiently causing extensive pollution to the environment. This paper presents a synthesis on what pellet is, the characteristic of pellet, the raw materials used for pellets production, biomass pelletizing process and description of a typical biomass pelletizing operation. Previous research that has been carried out on pellet production from biomass residues and application as domestic fuel has also been reviewed and cited in this paper.
\end{abstract}

Keywords-Biomass residue, Pelletizing, Characteristics, Domestic fuel.

\section{INTRODUCTION}

It is known generally that burning fossil fuels and deforestation are the major contributors to anthropogenic climate change. The use of biomass as an alternative energy source provides substantial socio-economic and environmental benefits, compensating its localized nature for its high availability and carbon-neutral raw material for the production of energy.

However, bio-fuels have low bulk densities of $80-150$ $\mathrm{kg} / \mathrm{m}^{3}$ for herbaceous and $150-200 \mathrm{~kg} / \mathrm{m}^{3}$ for woody biomass (Tumuluru et al. 2010). This limit their use to areas around their origin; plus, their heterogeneity is considered when it comes to moisture and loose nature, among others. These drawbacks are restrictive factors for their energy use (Arranz, 2011).

Many of the developing countries produce huge quantities of agro residues but they are used inefficiently causing extensive pollution to the environment. The major residues are rice husk, coffee husk, coir pith, jute sticks, bagasse, groundnut shells, mustard stalks and cotton stalks. Sawdust, a milling residue is also available in huge quantity (Grover and Mishra 1996).

The least-expensive biomass resources are these residues from wood or agro-processing operations since they are basically considered as waste. These residues have been highly promoted to be used in various heating systems, during the past decades. Compared to fossil fuel, most biomass residues have higher moisture content and lower density, thus making them technically unsuitable for direct use due to combustion and handling problems. Nevertheless, densification of biomass minimizes these disadvantages being a process that compress these raw materials in order to obtain denser fuels, with homogeneous properties and size. It improves biomass handling characteristics, increases the volumetric calorific values, and reduces transportation, collection, and storage costs (Markson et al. 2013; Grover and Mishra 1996). Among the different techniques that are available, pelletizing is currently the most extended one (Poddar, 2014).

The global pellet production has considerably increased for the last few years. Between 2006 and 2012, pellet production worldwide grew from 7 to 19 million tons (Duca, 2014), with Europe and North America being responsible for, practically, the whole production and consumption of densified products. The use of pellets is insignificant in developing countries: The pellets market for Africa, Asia and South America combined production is 
only 0.3 million tons/year in 2009 (Pirraglia et al., n.d. cited by Deepak, 2012).

The growth in pellet consumption has resulted in more diversity, when it comes to the use of raw materials for pellet manufacture. Consequently, the industry has started looking for products, such as wastes obtained from forestry, agriculture or a combination of the latter, currently obtaining a wide range of these products (Sepúlveda, 2014). In spite of the huge raw materials, pelletizing technologies is yet to get a strong foothold in many developing countries because of the technical constraints involved and the lack of knowledge to adapt the use of these technologies to suit local conditions (Grover and Mishra 1996). Overcoming the many operational problems associated with this technologies and ensuring the quality of the raw material used are crucial factors in determining its commercial success for use as domestic fuels. In addition, the importance of these technologies lies in conserving wood a commodity extensively used as domestic fuel in developing countries, leading to the widespread destruction of forests.

This research report aims to review pellet production from biomass residue and characterization for application as domestic fuel in developing countries. It is a key to the problem of environmental pollution caused by the inefficient use of biomass residues and long term solution to mitigate the problems of deforestation.

\section{PREVIOUS RESEARCH}

It is difficult to find information about the levels of pellet production and application in the developing countries. This is because the use of pellet is insignificant in developing countries. However, there is some global information on densified biomass fuels (DBFs) available, but most of the information does not separate between different kinds of DBFs. Hence, previous research on the production of pellets and application as domestic fuel will include both pellets and briquettes from wood and agricultural residue.

Gravalos et al. (2010), conducted an experimental study on calorific energy values of biomass residue pellets for heating purposes. The fuel samples used, were biomass residues of agricultural (cotton, cardoon, etc.) and forest (pine, fir, beech, etc.) wastes. The experimental results obtained are encouraging and show that these materials can be used as alternative fuels.

Roos and Brackley (2012), examines the three major wood pellet markets in Asia: China, Japan, and South Korea. In contrast to the United States, where most wood pellets are used for residential heating with pellet stoves, a majority of the wood pellets in Asia are used for co-firing at coal-fired power plants. A consistent Factor in these nations is that their governments are promoting renewable energy, leading to policies that are driving demand for wood pellets. As these countries strive to meet their renewable energy targets, their wood pellet consumption is projected to grow. Raju et al. (2014), in a work "Studies on development of fuel briquettes using locally available waste" stated that Briquettes of small size can be used in gasifies for power generation. If the plant sites are chosen properly for easy availability of raw material, the agricultural residues can be briquetted to reduce further transportation costs and associated pollution. This also improves the handling characteristics of biomass. The briquettes so obtained are very good fuels for local small scale industries and domestic purposes.

Trangkaprasith and Chavalparit, (2011) in a study "Heating value enhancement of fuel pellets from frond of oil palm" palm fronds were used as raw materials to produce pelletized fuel and waste glycerol as adhesive to reduce biodiesel production waste. The result from heating value analysis of frond is $17.25 \mathrm{MJ} / \mathrm{kg}$. Therefore it is potential to make them to be useful by pelletizing. These pellets could be used for alternative energy in the industrial segment by mixing with glycerol to get higher heating value. The aim of the research was to find optimum ratio of ingredients (ratio of raw material, waste glycerol, and water) for producing fuel pellet from such materials.

In a study "Characterization and feasibility of biomass fuel pellets made of Colombian timber, coconut and oil palm residues regarding European standards", Carlos et al. (2012), assessed the main properties of Colombian timber industry residues, coconut shells and oil palm shells and compare the characteristics of pellets made from these raw materials with European standards. Pellets made from these feedstocks have an average density between 850 and $1025 \mathrm{~kg} \cdot \mathrm{m}^{-3}$, low ash contents and heating values around $18000 \mathrm{~kJ} \cdot \mathrm{kg}^{-1}$. Coconut shell pellets have low compression ratios and problems during pretreatment; whereas, sawdust, wood shavings and oil palm shell pellets proved to be an attractive opportunity for pellet industry development in Colombia.

Tokan et al. (2016), tested 9 samples of rice husk pellets; $\mathrm{P}_{1}$ - $\mathrm{P}_{9}$ using water boiling test, $100 \mathrm{~g}$ of pellet sample P1, achieved $100^{\circ} \mathrm{C}$ in 6 minutes to boil $500 \mathrm{ml}$ of water while $100 \mathrm{~g}$ of pellet samples P6 and P7each achieved $100^{\circ} \mathrm{C}$ each in 8 minutes to boil $500 \mathrm{ml}$. Comparative studies of rice 
husk pellets and charcoal was also conducted, the results showed that $100 \mathrm{~g}$ of pellets burns uniformly under free convection with pale yellow flame and very little smoke while $100 \mathrm{~g}$ of charcoal burns irregularly and would require forced convection. With water boiling test, $100 \mathrm{~g}$ of charcoal sample achieved $100^{\circ} \mathrm{C}$ in 14 and 20 minutes to boil $500 \mathrm{ml}$ of water for $\mathrm{C} 1$ and $\mathrm{C} 2$ respectively. C3 did not achieve $100^{\circ} \mathrm{C}$. With calorific value ranging from $15.129-17.589$ $\mathrm{MJ} / \mathrm{kg}$, and good physical and combustion characteristic of the rice husk pellet, it can conveniently substitute for charcoal as a domestic fuel.

Comparative thermal analysis of the properties of coal and corn cob briquettes was conducted by Ikelle and Chukwuma (2014). The work involved the production of smokeless briquettes of various compositions from coal and corn cob using $\mathrm{CaSO} 4$ and starch as binders, while $\mathrm{Ca}(\mathrm{OH})$ was used as desulphurizing agent. The briquettes were produced in the following ratio of coal and rice husk such as 100:0, $80: 20,60: 40,40: 60,20: 80$ and 0:100 respectively. The proximate analyses of the raw coal sample yielded the following: ash content $12.56 \%$, moisture content $7.03 \%$, volatile matter $39.21 \%$, fixed carbon $41.2 \%$ and calorific value $117.18 \mathrm{KJ} / \mathrm{g}$. The corn cob gave the following values, ash content $12.56 \%$, moisture content $7.03 \%$, volatile matter $39.21 \%$, fixed carbon $41.2 \%$ and calorific value $61.46 \mathrm{KJ} / \mathrm{g}$. The prepared briquettes were sun dried for seven days, subjected to various tests to assess their fuel quality. Of the briquettes produced, the $80 \%$ coal: $20 \%$ corn cob briquettes produced using starch as binder had the following values; ash content $21.70 \%$, fixed carbon $45.01 \%$, moisture content $2.87 \%$, density $0.482 \mathrm{~g} / \mathrm{cm} 32$, volatile matter $30.42 \%$, porosity index $40.12 \%$, calorific value $153.23 \mathrm{KJ} / \mathrm{g}$, water boiling test 1.65 minutes, burning time 24.42 minutes, ignition time 41.22 seconds and sulphur content $6.05 \%$. For briquettes produced with $\mathrm{CaSO}$ as binder, $80 \%$ coal: $20 \%$ corn cob had the following values; ash content $27.69 \%$, fixed carbon $41.63 \%$, moisture content $2.77 \%$, density $0.503 \mathrm{~g} / \mathrm{cm} \mathrm{43,} \mathrm{volatile} \mathrm{matter} 27.91 \%$, porosity index $41.11 \%$, calorific value $134.46 \mathrm{KJ} / \mathrm{g}$, water boiling test 1.71 mins, ignition time $41.40 \mathrm{secs}$, burning time $25.91 \mathrm{mins}$ and sulphur content $7.42 \%$. The briquettes showed improved properties but with regards to combustible property, the briquettes made using starch as binder do have better qualities than those produced with $\mathrm{CaSO}$ as binder.

In a study "Using Agricultural Residues as a Biomass Briquetting: An Alternative Source of Energy", Maninder et al. (2012), showed that, raw material including rice husk, coffee husk, saw dust, ground nutshell and cotton stalks etc. were densified into briquettes at high temperature and pressure using different technologies. And also discuss the various advantages, factors affecting the biomass briquetting and comparison between coal and biomass briquetting. Maninder et al, (2012) concluded that apart from the transportation, storage and handling problems biomass briquetting have several advantages over coal, oil etc. so we have to use it for our domestic purposes like heating and cooking. Thus, biomass briquetting is an alternative source of energy.

In a work "Production and comparative study of pellets from maize cobs and groundnut shell as fuels for domestic use" Kyauta et al. (2015), handles the production and comparative study of solid fuels from agricultural waste (i.e. maize cobs and groundnut shell) that can serve as alternative energy sources for domestic use, using the densification process. The characteristics of the pellets determined were moisture content, ash content, combustion rate and calorific value. The result showed that groundnut shell pellets attained a higher temperature than maize cobs. The temperatures attained by $100 \mathrm{~g}$ of each type of fuel were $7560 \mathrm{C}$ and 600 OC for ground nut and maize cob pellets respectively. The result of the net calorific value test for maize cob was found to be $13.8 \mathrm{MJ} / \mathrm{kg}$ while that of groundnut shell pellets was $13.9 \mathrm{MJ} / \mathrm{kg}$. These results showed that the pellets are capable of generating heat that is sufficient for domestic use if appropriate appliances are used.

Sánchez et al. (2014), presents the results of a project focused on the development of briquettes from the waste wood (sawdust) resulting from the main waste from timber companies located in the Piura Region of Peru. This waste wood currently lacks a useful purpose, and its indiscriminate burning generates $\mathrm{CO}$ and $\mathrm{CO}_{2}$ emissions. Through a drying and compression process, sawdust briquettes were obtained with the following features: 19.8 $\mathrm{MJ} / \mathrm{kg}, 10 \%$ of humidity, $894 \mathrm{~kg} / \mathrm{m} 3,1.3 \%$ of ashes, $15,29 \%$ of fixed carbon, and $83.41 \%$ of volatile matter. The results achieved show that sawdust briquettes are a perfect substitute for the fuels coming from illegal logging of the dry forest reserve in Piura that are currently used in domestic stoves (e.g. charcoal, firewood) by $55.81 \%$ of families in the region. In order to investigate the acceptance of the substitute product, eleven communication and awareness workshops were conducted reaching over 600 families, in addition to product testing for 127 families in five low-income areas of the Piura region. 
Production and characterization of rice husk pellet was investigated as an alternative source of energy by Japhet $e t$ al. (2015), Pellets were produced from rice husk at three (3) pressures of compaction of $28 \mathrm{MPa}, 31 \mathrm{MPa}$ and $34 \mathrm{MPa}$ and three (3) particles sizes of $212 \mu \mathrm{m}, 300 \mu \mathrm{m}$ and $425 \mu \mathrm{m}$. The effects of compaction pressure on the properties of pellets were determined. The results showed that, the higher the compaction pressure the lower the porosity index and consequently the higher the bulk density. The fuel pellet's density affects its bulk thermal properties. This effect is seen, when $100 \mathrm{~g}$ of each pellet sample were combusted. Increased burning time of pellets was observed as the bulk density increases. The result also showed that the maximum calorific value of $17.589 \mathrm{MJ} / \mathrm{kg}$ was achieved with a compaction pressure of $34 \mathrm{MPa}$ and with particle size of $425 \mu \mathrm{m}$. also the minimum calorific value of $15.129 \mathrm{MJ} / \mathrm{kg}$ was achieved with a compaction pressure of $34 \mathrm{MPa}$ and with particle size of $212 \mu \mathrm{m}$.

Golinski and Foltynowicz (2012), in a study "Pellet - a Key to Biomass Energy" state that Pellet production is a rapidly growing business in many European countries. This fact is strongly connected with increasing role of biomass as a resource of clean energy. Future of pellet market is influenced by different political, economical, environmental and social aspects which create complex relations between suppliers of raw material, pellet producers and consumers. That is why standardization and quality control is being introduced in many countries, that allows to deliver better product which can compete with other fuels in terms of efficiency and impact on environment.

\section{MATERIALS AND METHODS}

\subsection{What Is Pellet}

Pellets are closely related to briquettes except that they have a smaller diameter and are more adapted to small scale use. Ashden (2011) refers to pellets as very small briquettes. There are a few different definitions of a pellet, but the one used in this study is as follows; "A Wood briquette (pellet) is a mass of ground fuel stuff moulded or pressed into a convenient unit with or without the aid of a binder" (written by Natividad, 1982 cited by Vinterbäck, 2000).

Pellets are a form of densified biomass with interesting opportunities for development of renewable energy. This solid fuel is mainly produced from wood residues but other biomass residues could be used. Pellets are an important renewable energy source that can easily be used in smallscale domestic systems. The dimensions of fuel pellets vary between 3 and $25 \mathrm{~mm}$ in diameter depending on the die block that is used in production. The length generally varies between 5 and $40 \mathrm{~mm}$. If the product exceeds $25 \mathrm{~mm}$ in diameter it is called a briquette (Morten et al., 2009). Two major factors have promoted the growth of the pellet fuel market. The first is the instability in price and consistent rise in the cost of fossil fuels, and the second is the increasing attention given to the effect of climate change on the environment caused by the use of fossil fuels. Other factors supporting the use of pellets are that they are a fuel that can be produced locally, from local wood and biomass residues. The local production of pellet can produce an affordable fuel, while creating local jobs and mitigating the problem of deforestation in developing countries.

\subsection{Characteristics of Pellet}

The main purpose of pelletizing a raw material is to reduce the volume and thereby increase the energy density. When densification has taken place, there are two quality aspects that need to be considered. Firstly, the pellet has to remain solid until it has served its purpose (handling characteristics). Secondly, pellet has to perform well as a fuel (fuel characteristics). The energy characteristics are other important issues when describing and comparing pellets with other fuels (Karlhager, 2008).

\subsection{Biomass Raw Materials for Pelletizing}

Biomass raw material base for the production pellets (briquettes) has been thoroughly described by Hirsmark (2002). There are a number of biomass materials that can be used for pellet (briquette) production. Wood residues as saw dust, wood chips, planer shavings, recycled wood and pure wood can all be used after milling. Agricultural residues as straw, hemp or reed canary gras s can be used. Short rotation coppice, e.g. Salix can also be used in pelletizing (briquetting) processes. Peat is another raw material suitable for pelletizing (briquetting) (Hirsmark 2002). There is no data of which raw material is the most important for briquette production (Karlhager, 2008). Hirsmark showed that saw dust and planer shavings are the two most common raw materials for pellet and briquette production though. In many developing countries which produce huge quantities of agro residues, the potential agro-residues which do not pose collection and drying problems, normally associated with biomass are rice husk, groundnut shells, coffee husk and coir waste (obtained by dry process). At present, loose rice husk, groundnut shells and other agro-residues are being used mostly by small scale boilers in process industries (Grover and Mishra 1996). "Fig." 1, shows some biomas s sources for pelletizing. 


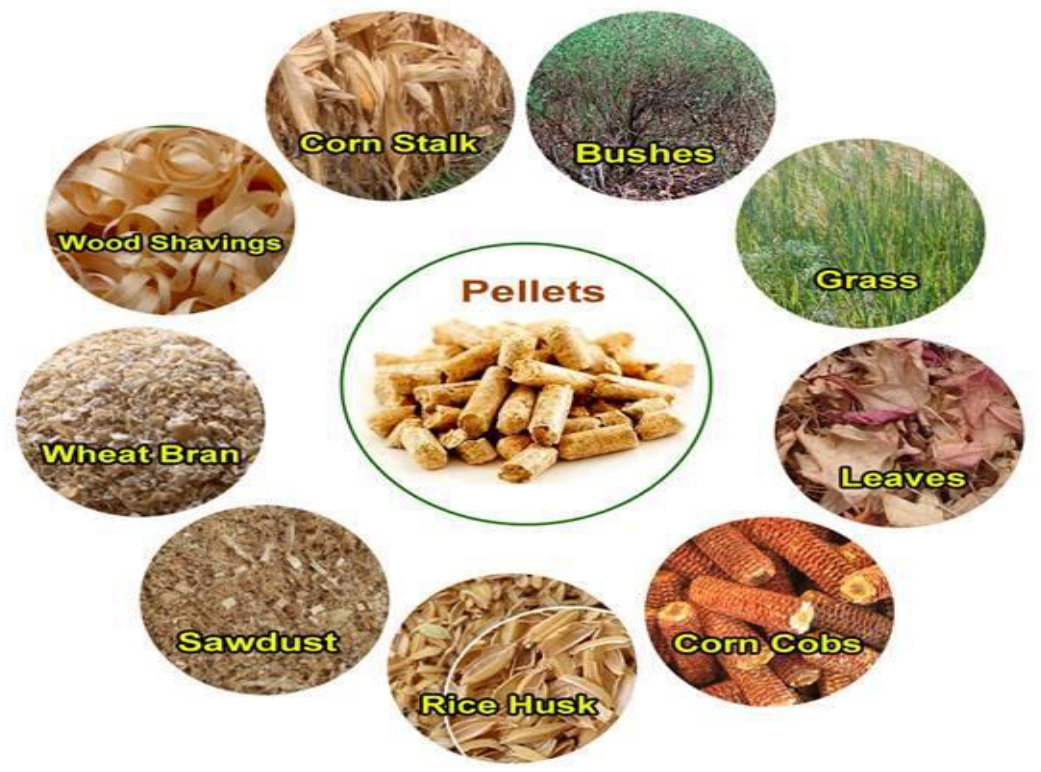

Fig.1: Biomass sources for pelletizing (Kiss and Alexa, 2014).

\subsection{Biomass Pelletizing Process}

Pelletizing is the process of densification of biomass to produce homogeneous, uniformly sized solid pieces of high bulk density which can be conveniently used as a fuel. The densification of the biomass can be achieved by any one of the following methods: (i) Pyrolysed densification using a binder, (ii) Direct densification of biomass using binders and (iii) Binder-less briquetting (pelletizing) (Karaosmanoglu, 2000). Depending upon the type of biomass, three processes are generally required involving the following steps:

I. Sieving - Drying - Preheating - Densification Cooling - Packing

II. Sieving - Crushing - Preheating - Densification Cooling - Packing

III. Drying - Crushing - Preheating - Densification Cooling - Packing

\subsection{Description of a Typical Biomass Pelletizing}

\section{Operation}

A typical biomass pelletizing operations consisting of three major unit operations - drying, size reduction (grinding), and densification (pelletizing) is shown in "Fig." 2.

The biomass is dried to about $10 \%$ (wb) in the rotary drum dryer. Superheated Steam dryers, flash dryers, spouted bed dryers, and belt dryers are also common in European countries (Stahl et al., 2004; Thek and Obernberger, 2004) but they are not used in North America (to the knowledge of the authors).
After drying, a hammer mill equipped with a screen size of 3.2 to $6.4 \mathrm{~mm}$ reduces the dried biomass to a particle size suitable for pelletizing. The ground biomass is compacted in the press mill to form pellets. The individual pellet density ranges from 1000 to $1200 \mathrm{~kg} / \mathrm{m}^{3}$. The bulk density of pellets ranges from 550 to $700 \mathrm{~kg} / \mathrm{m}^{3}$ depending on size of pellets. Pellet density and durability are influenced by physical and chemical properties of the feedstock, temperature and applied pressure during the pelletizing process (Mani et al., 2003). In some operations, the ground material is treated with super-heated steam at temperatures above $100^{\circ} \mathrm{C}$ before compaction. The superheated steam increases moisture and temperature of the mash causing the release and activation of the natural binders present in the biomass. Moisture also acts as a binder and lubricator (Robinson, 1984).

In some operations, binders or stabilizing agents are used to reduce the pellet springiness and to increase the pellet density and durability. Most widely used binders for pelletizing of animal feeds are calcium lignosulfonate, colloids, bentonite, starches, proteins and calcium hydroxide (Pfost, 1964; Tabil And Sokhansanj, 1996). Pfost and Young (1974) Reported that there was a significant increase in pellet durability when using colloids and calcium lingo-sulphonate as additives in the range of $2.6 \%$ by weight. Biomass from woody plants contains higher percentages of resins and lignin compared to agricultural crop residues (straw and stover). When lignin-rich biomass is compacted under high pressure and temperature, lignin 
becomes soft exhibiting thermosetting properties (van Dam et al., 2004). The softened lignin acts as glue.

The temperature of pellets coming out of the pellet mill ranges from $70^{\circ} \mathrm{C}$ to $90^{\circ} \mathrm{C}$. The elevated temperature is due to the frictional heat generated during extrusion and material pre-heating. Pellets are cooled to within $5^{\circ} \mathrm{C}$ of the ambient temperature in a cooler. The hardened cooled pellets are conveyed from the cooler to storage areas using mechanical or pneumatic conveying systems. Pellets may be passed over a screen to have fines removed and were weighed before being stored in enclosed storage areas (Mani et al., 2006).

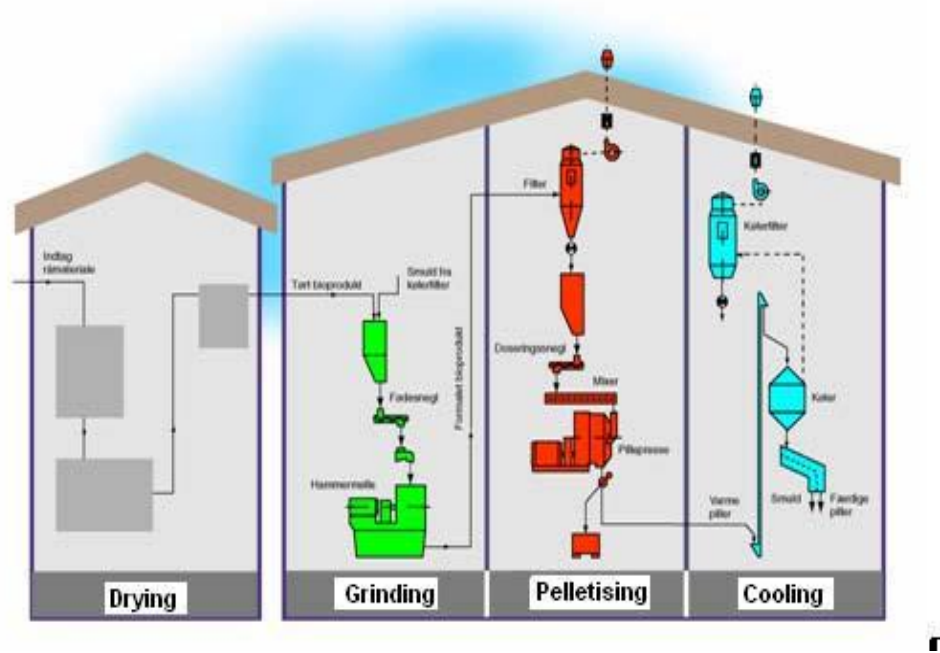

Fig.2: Flow diagram of the pelletizing process (Morten et al, 2009)

\section{DISCUSSION}

Biomass residues - wood and agricultural waste, have high potential to contribute to the energy needs of developing countries, but factors such as low density and high moisture content are some drawbacks, making them technically unsuitable for direct use. Densification technologies provide practical options for overcoming some of the inherent drawbacks of biomass (moisture content and low energy density being the most important). Pelletizing can be regarded as one of the well established densification procedure, gaining increasing popularity and acceptance in recent years in the developed countries. Which are mainly due to pellets dimensions (appropriate for automatic feeding and for application in small domestic appliances). In this paper, the characteristics of pellets, biomass raw materials for pelletizing, biomass pelletizing process and description of a typical biomass pelletizing operation were described. From previous research, it was shown that pellets with good handling and fuel characteristics could be produced from wood and agricultural waste. This will provide other alternatives for reducing problems caused by burning fossil fuels and deforestation which are the major contributors to anthropogenic climate change.

\section{CONCLUSIONS}

Massive production of fuel pellets from wood and agricultural waste, for application as domestic fuel could give a positive development to developing countries, where there are a lot of these resources and yet lack a sustainable source of biomass fuel supply.

Therefore, more research on different alternatives combination of raw materials for the production of pellet from wood and agricultural waste, on analysis of their characteristics and their behavior on combustion, and on the appropriate appliance for their application, should be performed, to encourage the use of pellet as domestic fuel in developing countries.

\section{REFERENCES}

[1] Arranz, J. I. (2011). Analysis of Densified of the Combination from Different Biomass Waste. Doctoral Thesis, University of Extremadura, Badajoz, Spain.

[2] Ashden Technology (2011). Biomass Briquettes and Pellets. Retrieved April 28, 2014, from: httpwww.ashden.orgfilesfactsheetsashden briquettes and pellets.pdf

[3] Carlos A. F. N., Joachim J., and Fabio E. S. V. (2012). Characterization and feasibility of biomass fuel pellets made of Colombian timber, coconut and 
oil palm residues regarding European standards, Environmental Biotechnology 8 (2), 67-76

[4] Deepak, A. (2012). Reinventing the Fire - Business Models for Pellet Production as a Cooking Fuel in Developing Countries

[5] Duca, D.; Riva, G.; Foppa Pedretti, E.; Toscano, G. (2014). Wood pellet quality with respect to $\mathrm{EN}$ 14961-2 standard and certifications. Fuel, 135, 9-14.

[6] Fabian M. (2003). An introduction to anaerobic digestion of organic wastes. Scotland Remade

[7] Golinski, T. and Foltynowicz, Z. (2012). Pellet - a Key to Biomass Energy; International Journal of Economic Practices and Theories, Vol. 2, No. 4.

[8] Gravalos I., Kateris D., Xyradakis P., Gialamas T., Loutridis S., Augousti A., Georgiades A. and Tsiropoulos Z. (2010). A STUDY ON CALORIFIC ENERGY VALUES OF BIOMASS RESIDUE PELLETS FOR HEATING PURPOSES : Forest Engineering: Meeting the Needs of the Society and the Environment, Padova - Italy

[9] Grover, P. D., and S. K. Mishra. (1996). Biomass briquetting: Technology and practices. Regional Wood Energy Development Program in Asia. Field document No. 46. Bangkok, Thailand, Food and Agriculture Organization of the United Nations.

[10] Hirsmark, J. (2002). Densified Biomass Fuels in Sweden: Country report for the EU/INDEBIF project. Swedish University of Agricultural Sciences, Uppsala.

[11] Ikelle, I. I. and Chukwuma, A. (2014). Comparative Thermal Analysis of the Properties of Coal and Corn Cob Briquettes. IOSR Journal of Applied Chemistry (IOSR-JAC), e-ISSN: 2278-5736.Volume 7, Issue 6 Ver. I. PP 93-97

[12] Japhet, J. A., Tokan, A., and Muhammad, M. H. (2015). Production and Characterization of Rice Husk Pellet; American Journal of Engineering Research (AJER), Volume-4, Is sue-12, pp-112-119

[13] Karaosmanoglu F. (2000). Biobriquetting of rapeseed cake, Energy Sources 22(3), 257-267.

[14] Karlhager, J. (2008). The Swedish market for wood briquettes - Production and market development. Department of Forest Products, SLU, Uppsala

[15] Kiss, I. and Alexa, V., (2014). Short Introspections Regarding the Sawdust Briquetting as Sustainable Solution for the Environment, Analecta, Vol. 8, No. 2.

[16] Kyauta E. E., Adisa A.B., Abdulkadir L.N. and Balogun S., (2015). Production and Comparartive Study of Pellets from Maize Cobs and Groundnut
Shell as Fuels for Domestic Use. American Journal of Engineering Research (AJER) Volume-4, Issue-1, pp97-102

[17] Mani, S., Sokhansanj, S., Bi, X. and Turhollow, A. (2006). Economics of Producing Fuel Pellets from Biomass; Applied engineering in agriculture Vol. 22(3): 421-426.

[18] Maninder, Kathuria, R. S. and Grover, S. (2012). Using Agricultural Residues as a Biomass Briquetting: An Alternative Source of Energy, IOSR Journal of Electrical and Electronics Engineering (IOSRJEEE), ISSN: 2278-1676 Volume 1, Issue 5, PP 11-15

[19] Mani, S., Tabil, L. G. and Sokhansanj, S. (2003). An overview of compaction of biomass grinds. Powder Handling and Processing 15(3): 160-168.

[20] Markson, I.E., Akpan, W.A. and Ufot, E., (2013). Determination of Combustion Characteristics of Compressed Pulverized Coal-Rice Husk Briquettes; International Journal of Applied Science and Technology, Vol. 3 No. 2, Pp 61 - 64

[21] Morten T. H., Anna R. J., Sandra H. and Patrick B. (2009). English Handbook for Wood Pellet Combustion

[22] Pfost, H. B. 1964. The effect of lignin binders, die thickness and temperature on the pelleting process. Feedstuffs 36(22): 20, 54.

[23] Pfost, H. B., and L. R. Young. (1974). Effect of colloidal binder and other factors on pelleting. Feedstuffs 45(49): 22.

[24] Poddar, S.; Kamruzzaman, M.; Sujan, S. M. A.; Hossain, M.; Jamal, M. S.; Gafur, M. A. and Khanam, M. (2014). Effect of compression pressure on lignocellulosic biomass pellet to improve fuel properties: Higher heating value. Fuel, 131, 43-48.

[25] Raju, Ch. A. I., Satya, M., Praveena U. and Jyothi, K. R. (2014). Studies on Development of Fuel Briquettes Using Locally Avaliable Waste; M. Satya et al Int. Journal of Engineering Research and Applications ISSN : 2248-9622, Vol. 4, Issue 3( Version 1), March 2014, pp.553-559

[26] Robinson, R. (1984). Pelleting. In Manufacture of Animal Feed, ed.D. A. Beaven, 50-53. Herts, England: Turrent-Wheatland Ltd.

[27] Roos, J. A. and Brackley, A. M. (2012). The Asian Wood Pellet Markets. GenmTech Rep. PNW-GTR861. Portland, OR. U.S. Department of Agriculture, Forest Service, Pacific Northwest Research Station. 25 p. 
[28] Sánchez, E. A., Pasache, M. B. and García, M. E. (2014). Development of Briquettes from Waste Wood (Sawdust) for Use in Low-income Households in Piura, Peru; Proceedings of the World Congress on Engineering 2014 Vol II, WCE 2014, London, U.K.

[29] Sepúlveda, F. J. (2014). Selective Use for the Integral Valorization of Wastes from Cork Industry. Ph.D. Thesis, University of Extremadura, Badajoz, Spain.

[30] Stahl, M., K. Granstrom, J. Berghel, and R. Renstrom. (2004). Industrial processes for biomass drying and their effects on the quality properties of wood pellets. Biomass and Bioenergy 27(6): 621-628.

[31] Tabil, L., and S. Sokhansanj. (1996). Process conditions affecting the physical quality of alfalfa pellets. Applied Engineering in Agriculture 12(3): 345-350.

[32] Thek, G., and I. Obernberger. (2004). Wood pellet production costs under Austrian and in comparis on to Swedish framework conditions. Biomass and Bioenergy 27(6): 671-693.

[33] Tokan, A., Muhammad, M. H., Japhet, J. A. andKyauta, E. E. (2016). Comparative Analysis of the Effectiveness of Rice Husk Pellets and Charcoal As Fuel For Domestic Purpose, IOSR Journal of Mechanical and Civil Engineering (IOSR-JMCE), Volume 13, Issue 5 Ver. VI, PP 21-27

[34] Trangkaprasith K. and Chavalparit O. (2011). Heating Value Enhancement of Fuel Pellets from Frond of Oil Palm. 2010 International Conference on Biology, Environment and Chemistry IPCBEE vol.1

[35] Tumuluru J. S., Wright C. T., Kevin L. K and Hess J. R (2010). A Review on Biomass Densification Technologies for Energy Application

[36] van Dam, J. E. G., van den Oever, M. J. A., Teunissen, V., Keijsers, E. R. P. and Peralta, A. G. (2004). Process for production of high density/high performance binderless boards from whole coconut husk - Part 1: Lignin as intrinsic thermosetting binder resin. Industrial Crops and Products 19(3): 207-216.

[37] Vinterbäck, J. (2000). Densification of Wood and Bark for Fuel Production - a Story of 150 years. In: Wood Pellet Use in Sweden: A systems approach to the residential sector. Silvestria 152. Swedish University of Agricultural Sciences, Uppsala. 